\title{
El dolor a través del arte
}

\author{
Pain through art \\ Marlene Vanessa Salcido Reyna* \\ `Especialidad en Traumatología y Ortopedia, Hospital General de Mexicali. Baja California, México.
}

\begin{abstract}
Resumen
El dolor es una experiencia desagradable asociada con un daño tisular real o potencial con componentes sensoriales, emocionales, cognitivos y sociales. A través de los artistas podemos mejorar la comprensión del dolor; Frida Kahlo, la artista mexicana, logra con sus cuadros compartirnos la agonía de su vida; Renoir por el contrario hace obras majestuosas valiéndose de lienzos y cojines que sujetan su cuerpo mientras pinta; Jawlensky nos enseña en sus cuadros el efecto del dolor desde el inicio de sus cuadros hasta el final, los tonos de los colores, las líneas, nos transmiten más allá de la palabra dolor; Dokumaci desafía la observación y la simplicidad de la vida cuando algo tan sencillo como vestirse es imposible para alguien con artritis reumatoide. El primer paso para erradicar o controlar el dolor es la comprensión de su extensión, la asociación para el estudio del dolor lo define con componentes sensoriales, emocionales, cognitivos y sociales.
\end{abstract}

Palabras clave: Dolor, arte, artistas, historia, Frida Kahlo.

\begin{abstract}
Pain is an unpleasant experience associated with actual or potential tissue damage with sensory, emotional, cognitive and social components. Through artists we can improve our understanding of pain, Frida Kahlo, the Mexican artist, manages to share with us the agony of her life through her paintings, Renoir, on the other hand, makes majestic works using canvases and cushions that support his body while he paints, Jawlensky shows us in his paintings the effect of pain from the beginning of his paintings to the end, the tones of the colors, the lines, transmit us beyond the word pain, Dokumaci, challenges observation and the simplicity of life when something as simple as getting dressed is impossible for someone with rheumatoid arthritis. The first step to eradicate or control pain is the understanding of its extent, the association for the study of pain defines it with sensory, emotional, cognitive and social components.
\end{abstract}

Keywords: Pain, art, artists, history, Frida Kahlo.

\section{Introducción}

El dolor se define como una experiencia angustiosa o desagradable asociada con un daño tisular real o potencial con componentes sensoriales, emocionales, cognitivos y sociales. ${ }^{1}$ La definición del dolor debe ser sencilla; sin embargo, debe capturar el daño tisular, la experiencia personal y especificar los componentes presentes en el dolor. ${ }^{2}$

Al actualizar la definición de dolor por la Asociación Internacional para el Estudio del Dolor (IASP por sus siglas en inglés), se incluye el efecto adverso sobre la

Correspondencia:

Marlene Vanessa Salcido Reyna

Hospital General de Mexicali,

Calle del Hospital S/N,

Centro Cívico, Mexicali, B.C.

E-mail: drasalcidoreyna@gmail.com función, el bienestar social y bienestar psicológico, la descripción verbal es sólo una de las conductas para expresar el dolor. ${ }^{2}$ En este contexto se realizó una búsqueda sistemática con el objetivo de conocer la visualización del dolor a través de la experiencia del artista, ya sea al padecer la enfermedad o al observarla.

\section{Material y métodos}

Se realizó una búsqueda en PubMed, Cochrane, LILACS, Google Scholar, utilizando los términos «arte y dolor», en inglés y en español, se incluyeron todos

Recibido: 24-05-2021. Aceptado: 25-05-2021.

Citar como: Salcido RMV. El dolor a través del arte. Orthotips. 2021; 17 (2): 90-93. https://dx.doi.org/10.35366/99902 


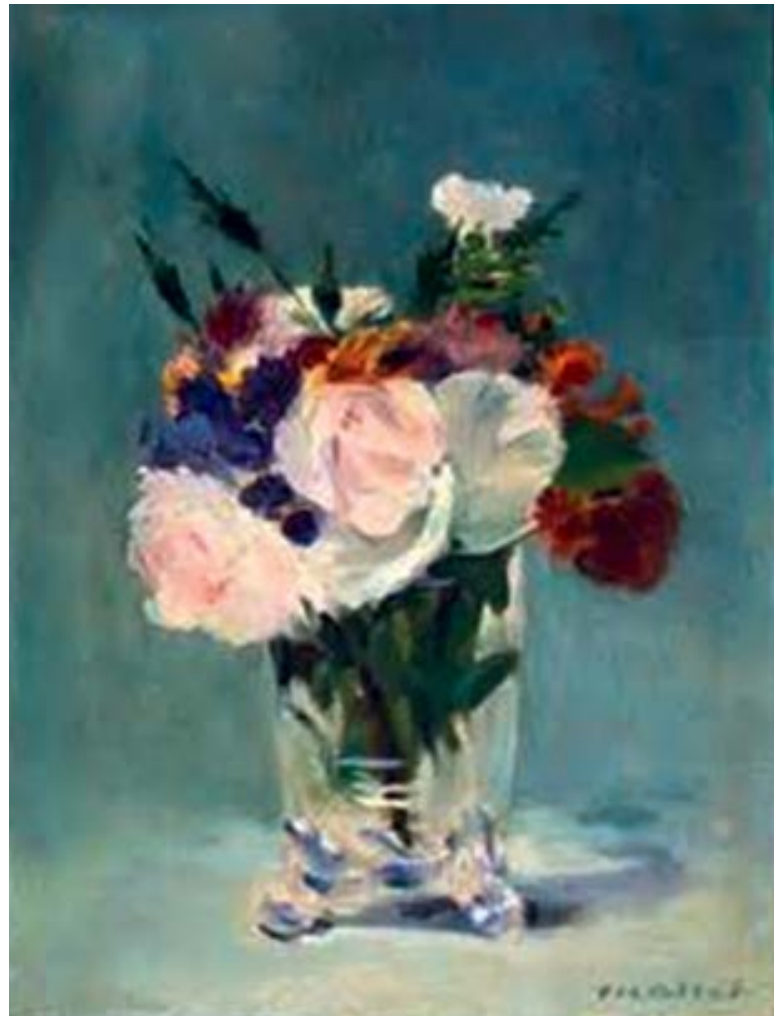

Figura 1: Flores en un jarrón de cristal, una de las últimas pinturas de Manet (1882).

los artículos que presentaran una narrativa sobre la evolución del dolor en el artista o el arte como una expresión del dolor, también se incluyeron resúmenes que mencionaban la presencia de patología dolorosa presente en las pinturas.

Se encontraron 20 artículos que cumplían los criterios de elegibilidad, la publicación más antigua es de 1989 escrita en Bélgica, se escribe un artículo por año aproximadamente, la mayoría es de Estados Unidos de América con cuatro artículos, por especialidad cuatro pertenecen a reumatología y cuatro más a neurología.

Édouard Manet (1832-1883) es considerado el padre del impresionismo e incluso del arte moderno del siglo XX. Durante sus primeros 40 años, desarrolló una enfermedad agresivamente devastadora asociada con un desequilibrio de la marcha, falta de coordinación y dolores severos, muy sugestivo de tabes dorsal. Los años más productivos estuvieron fuertemente marcados por la enfermedad; ocho años antes de su muerte, Manet comenzó a desarrollar dolor en las extremidades inferiores junto con des- equilibrio progresivo de la marcha, es sorprendente cómo las pinturas de naturaleza muerta con flores puedan ser consideradas la cumbre de Manet en arte y calidad y de hecho su logro técnico y emocional es extraordinario (Figura 1). ${ }^{3}$

Baruch Elron es un personaje muy conocido dentro del ámbito de las artes en Israel, conoció el dolor, se le amputó la pierna y sufrió el dolor crónico del miembro fantasma, en esta pintura titulada Dolor agudo utilizó colores otoñales para expresar la desolación tanto del cuerpo como del espíritu como causa del dolor que no remite, la pintura se ha hecho muy popular entre investigadores, médicos especialistas y otros profesionistas en el campo del dolor, fue seleccionada por la Federación Europea en los capítulos de la IASP como ilustración central para la Semana Europea Contra el Dolor (Figura 2). ${ }^{4}$

La artritis reumatoide severa del pintor Alexej von Jawlensky ocupó su lugar al final de la historia del arte, fue el primer pintor del siglo XX en crear una gran obra artística en un cambio extraordinario de imágenes individuales a series extensas de rostros principalmente humanos. La enfermedad de Jawlensky se caracterizó por un curso rápidamente progresivo con dolor intenso e inicio rápido de la discapacidad y en última instancia inmovilización completa, siendo llamado el pintor del alma humana. ${ }^{5}$ En los primeros años después del inicio de la enfermedad se notó un cambio en la serie de cabezas abstractas y se asignó

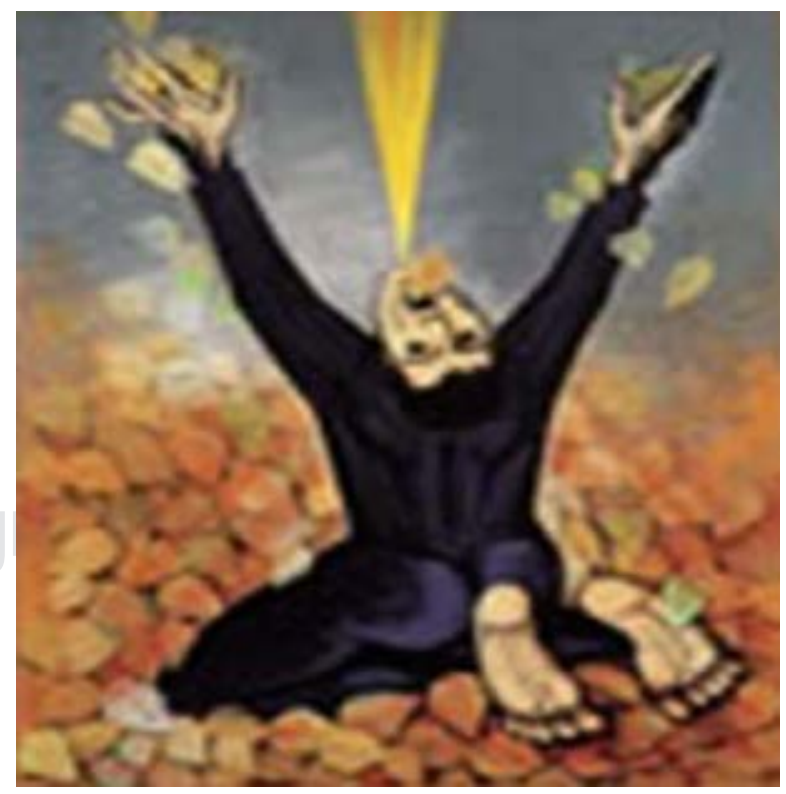

Figura 2: Pintura titulada Dolor agudo de Baruch Elron. 


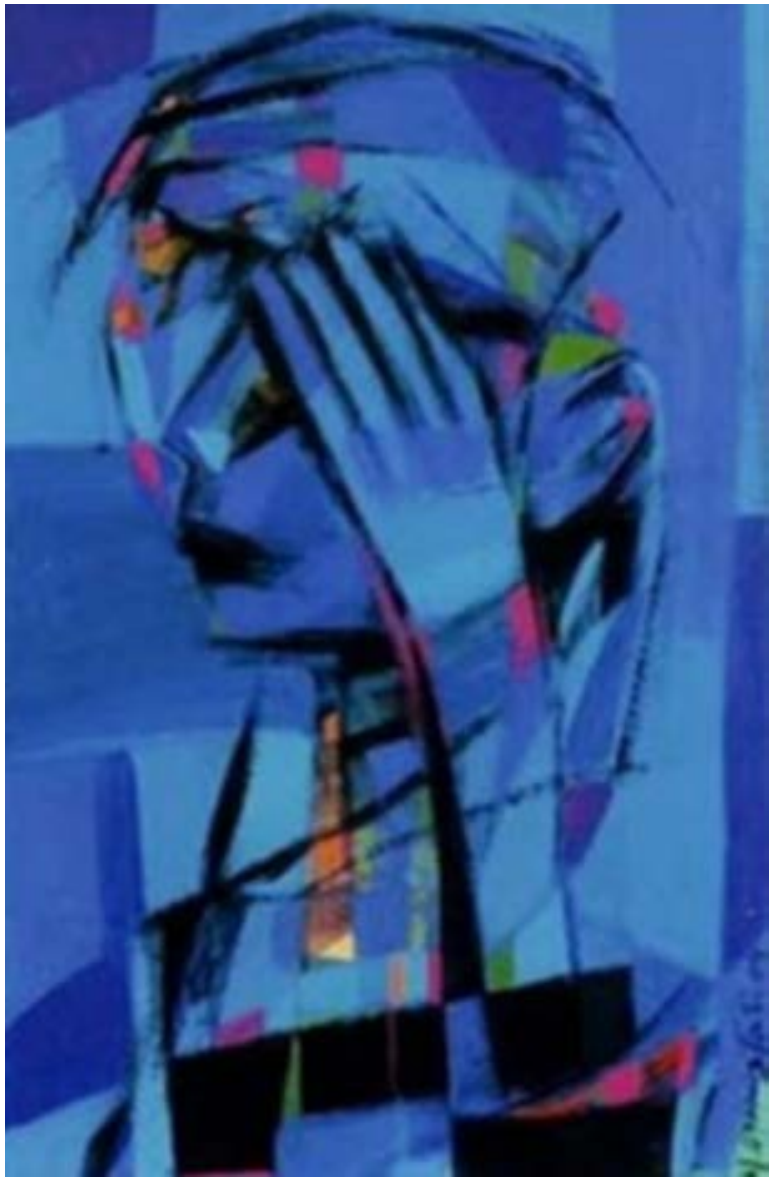

Figura 3:. El dolor, obra maestra de Mónica Ozámiz, representa a los que sufren fibromialgia.

la influencia de la enfermedad como la más amplia y despreocupada aplicación de color y apariencia más oscura y más brillante de las cabezas. ${ }^{5}$

El famoso pintor Pierre-Auguste Renoir (18411919) padecía artritis reumatoide, el pintor impresionista francés más popular utilizó su creatividad para desarrollar sus propios equipos de asistencia para pintar a pesar de su enfermedad. ${ }^{5}$

Mónica Ozámiz, licenciada en Bellas Artes, especialista en pintura en la Facultad de San Fernando, Madrid, en su pintura revela un expresionismo que reúne muchos elementos constructivistas, con técnica mixta dibuja El dolor, su obra maestra (Figura 3), con ella la artista quiso representar a aquéllos que sufren de fibromialgia, la cual padece. ${ }^{4}$

Arseli Dokumaci es una artista de origen francés con diagnóstico temprano de artritis reumatoide, a través de sus pinturas expresa la complejidad de la vida común, una de sus obras se llama The Art of the Zipping up, podemos observar desde una perspectiva superior una mujer, cuya mano derecha está deformada un poco más que la izquierda y no puede abducir sus hombros ni realizar una rotación interna, los dedos de la mano derecha son más gruesos y esta tarea simple se vuelve una tarea compleja secundaria a la deformidad explicita e implícita, esta misma autora crea otra obra llamada Some arms carry things. Some arms are carried in pockets, en la cual se observa la deformidad de hombros y hace alusión al uso de bolsillos cuando el dolor hace imposible incluso mantener la posición de los hombros. ${ }^{6}$

Frida Kahlo es una de las artistas mexicanas más conocidas del siglo XX, tanto su vida como mujer, como su trabajo como artista estuvieron profundamente influenciados por las imágenes radiológicas que encontró como paciente, ${ }^{5}$ de sus 143 pinturas, 55 son autorretratos que a menudo plasman sus heridas físicas y psicológicas, además de su accidente donde sufrió múltiples abortos espontáneos y pasó gran parte de su vida enyesada, con aparatos ortopédicos y confinada a la cama haciendo del dolor y del sufrimiento el tema natural en su trabajo. ${ }^{7}$

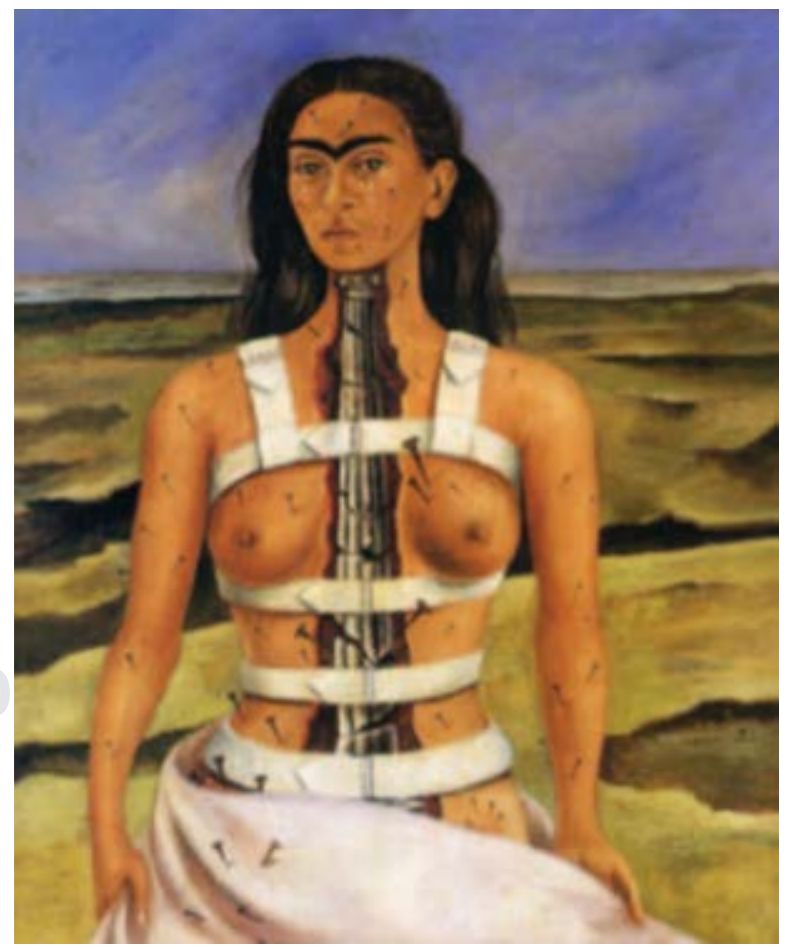

Figura 4: La columna rota de Frida Kahlo (1944). 


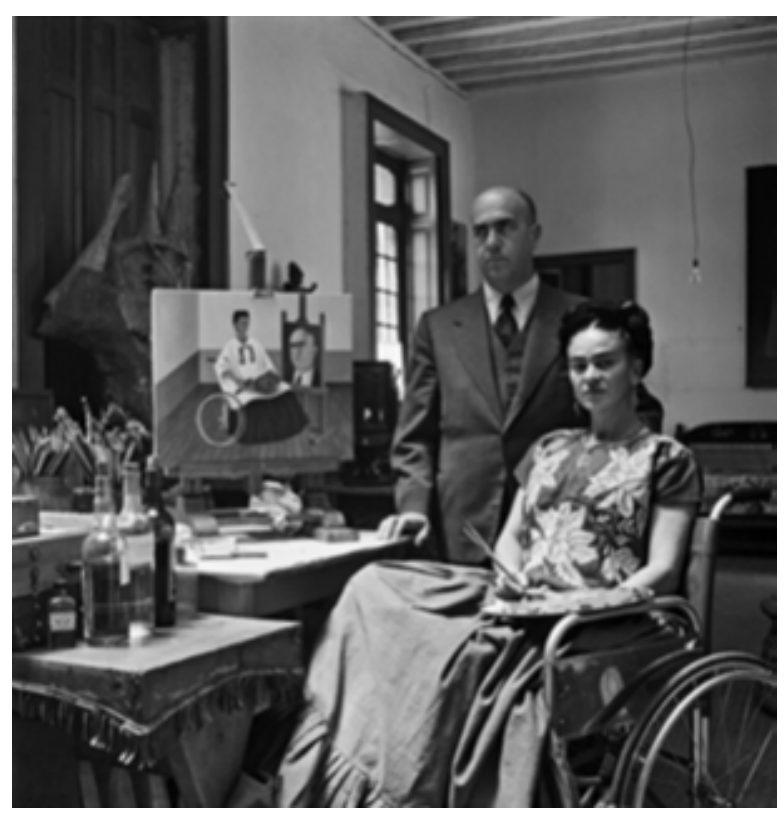

Figura 5: Foto con el autorretrato que le dio Frida Kahlo al Dr. Farill.

Pintada en 1944 al óleo, La columna rota (Figura 4) representa el cuello y el torso de la artista abiertos por la línea media, revelando una columna irónica fracturada que sustituye a su columna vertebral, el fondo representa ese aspecto social y desolador que compone al dolor. ${ }^{7}$

En la versión pintada del Dr. Farill, que realizó Frida, sus cejas están unidas como las de ella, como si hubiera absorbido parte de su identidad, las poses de la foto reflejan cuidadosamente las del autorretrato, tres años después de que esta foto fuera tomada Frida murió a los 47 años (Figura 5). ${ }^{8}$

La novelista Virginia Woolf una vez describió las limitaciones del lenguaje para transmitir sufrimiento. El arte de Kahlo no está destinado a consolar, está destinado a desafiar. Nos desafía como médicos a salirnos de nuestras rutinas científicas y clínicas, mirar la experiencia de la enfermedad y lesiones desde la perspectiva del paciente, nos desafía como seres humanos a recoger y responder la experiencia de cada paciente en toda su complejidad. ${ }^{7}$

\section{Conclusión}

El arte constituye una forma importante de expresión del ser humano, nos permite a través del artista vivir la experiencia o entender más allá del lenguaje verbal, a través de la vista, el color, las formas y los detalles permiten percibir el pensamiento y los sentimientos presentes en la enfermedad, constituye siempre un reto para el médico entender la complejidad y la extensión del dolor.

Estas obras nos permiten ver más allá de la patología, al ser humano y el impacto que el médico puede tener en el curso de la enfermedad, en el arte es en sí una herramienta ideal para la expresión de emociones, para que el paciente y el médico puedan comprender la experiencia, de ahí que su importancia es invaluable.

\section{Referencias}

1. Williams ACC, Craig KD. Updating the definition of pain. Pain. 2016; 157 (11): 2420-2423.

2. Aydede M. Does the IASP definition of pain need updating? Pain Rep. 2019; 4 (5): e777.

3. Bogousslavsky J, Tatu L. Édouard Manet's Tabes Dorsalis: from painful ataxia to phantom limb. Eur Neurol. 2016; 76 (1-2): 75-84.

4. Cordero Escobar I. El dolor y el arte... un acercamiento a la realidad. Rev Cuba Anestesiol Reanim. 2012; 11 (1): 5-18.

5. Zeidler H. Great artists with rheumatoid arthritis: what did their disease and coping teach? Part I. Pierre-Auguste Renoir and Alexej von Jawlensky. J Clin Rheumatol. 2012; 18 (7): 376-381.

6. Kuczewski MG, Mejias-Beck J, Blair A. Good sanctuary doctoring for undocumented patients. AMA J Ethics. 2019; 21 (1): E78-E85.

7. Gunderman RB, Hawkins CM. The self-portraits of Frida Kahlo. Radiology. 2008; 247 (2): 303-306.

8. Launer J. Frida Kahlo and her doctors. Postgrad Med J. 2018; 94 (1112): 369-370.

\section{Conflicto de intereses}

El autor no tiene ningún conflicto de intereses en relación con este manuscrito. 